Actividad Física y TDAH

\title{
ACTIVIDAD FÍSICA Y TDAH: EVIDENCIA SOBRE EL DESARROLLO, EFECTOS NEUROCOGNITIVOS A CORTO Y LARGO PLAZO Y SUS APLICACIONES
}

\author{
(Versión traducida al español) \\ Eduardo Esteban Bustamante ${ }^{1}$, María Enid Santiago-Rodriguez¹, Jared Donald Ramer, \\ Guilherme Moraes Balbim ${ }^{1}$, Tara Gisela Mehta ${ }^{1}$, Stacy Lynn Frazier ${ }^{2}$ \\ ${ }^{1}$ University of Illinois at Chicago, ${ }^{2}$ Florida International University \\ Envío original: 2018-09-25. Reenviado: 2019-04-10. Aceptado: 2019-04-23. Publicado: 2019-06-28.
}

\begin{abstract}
RESUMEN
PROBLEMA: El trastorno por Déficit de Atención e Hiperactividad (TDAH) está caracterizado por retrasos en el desarrollo neurobiológico. La actividad física (AF) puede influir en varios de los mecanismos neurocognitivos que también son afectados por el TDAH, por lo tanto, puede considerarse parte del tratamiento y manejo del TDAH. Esta revisión sobre TDAH resumirá estudios que evaluaron AF, aptitud física y coordinación motora. CRITERIOS DE INCLUSIÓN/EXCLUSIÓN: Fueron incluidos artículos sobre AF en la niñez en el espectro de TDAH. RESULTADOS: Estudios transversales: los niños con TDAH presentan niveles de AF más altos que aquellos niños aparentemente saludables. La niñez coincide con oportunidades para participar en juego libre, pero esta ventaja es reducida durante la adolescencia, en la cual la AF es estructurada y menos inclusiva. Durante la adultez, las personas con TDAH están más propensas a ser obesas y a no adoptar las recomendaciones de estilos de vida saludables. Estudios longitudinales: AF durante etapas tempranas predice la severidad de los síntomas del TDAH en etapas subsecuentes. Otros estudios: la AF moderada de corta duración brinda beneficios neurocognitivos. Los resultados sobre intervenciones de varias semanas difieren según la variable de interés y el grupo con el cual es comparada la intervención. CONCLUSIÓN/IMPLICACIONES: Las intervenciones de AF que retan las habilidades cognitivas y destrezas de movimientos brindan beneficios a los niños con TDAH. Además, estimulan a niños, niñas y adolescentes a participar en AF estructurada, a cumplir con la recomendación de AF y a incluir AF de corta duración como parte de las rutinas diarias.
\end{abstract}

Palabras Claves: ejercicio, aptitud física, coordinación motora, salud mental, desarrollo en la niñez

\section{RESUMEN COLOQUIAL:}

Algunos niños pueden presentar dificultad para prestar atención, controlarse ellos mismos y para permanecer sentados. Estos síntomas son parte del trastorno por Déficit de Atención e Hiperactividad (TDAH). Las terapias psicológicas y farmacológicas son tratamientos convencionales para tratar el TDAH. Varios hallazgos sobre estudios transversales, longitudinales e intervenciones de actividad física de corta duración y de varias semanas indican que la actividad física brinda beneficios a la función cerebral, al razonamiento, y la conducta de los niños con TDAH. La actividad física que reta cognoscitivamente al niño(a) tiende a brindar mayores beneficios cognitivos. Por ejemplo, la actividad física aeróbica de intensidad moderada 
y de corta duración ha demostrado que mejora los niveles de energía, enfoque y el desempeño en tareas relacionadas a la solución de problemas. Sin embargo, se desconoce cómo la actividad física puede influenciar la conducta de niños y niñas cuando están rodeados de las distracciones de un salón de clases. Desafortunadamente, los niños con TDAH están más propensos a no cumplir con la recomendación de tiempo en pantalla. También, están más propensos a ser sedentarios y obesos cuando sean adultos porque tienen menos oportunidades para desarrollar sus destrezas motoras o participar de actividad física estructurada (ej. Deportes) durante la niñez en comparación con los niños(as) aparentemente saludables.

\section{INTRODUCCIÓN}

El trastorno por Déficit de Atención e Hiperactividad (TDAH) es el trastorno mental durante la niñez más común en los Estados Unidos. El mismo afecta aproximadamente 5.1 millones de niños y niñas, esto es, 9\% de los niños y adolescentes estadounidenses (Visser, Deubler, Bitsko, Holbrook, \& Danielson, 2016). En América Latina, la prevalencia del TDAH es similar a la estadounidense; sin embargo, varía por país o territorio. En Brasil (Arruda, Querido, Bigal, \& Polanczyk, 2015) y Puerto Rico (Bird et al., 2006) la prevalencia varía entre 5-6\%; mientras que en Chile (Vicente et al., 2012) y Venezuela (Montiel, Peña, Montiel-Barbero, \& Polanczyk, 2008) llega hasta un 10\%. EI TDAH se caracteriza por un patrón persistente de problemas de atención y/o hiperactividad o impulsividad que interfiere con las funciones del diario vivir y el desarrollo. La etiología del TDAH es desconocida y la heterogeneidad de deficiencias neurobiológicas (cerebro más pequeño, asimetrías en las estructura de los hemisferios y retrasos en el desarrollo de la corteza cerebral) sugieren la posibilidad de múltiples razones para que ocurra el trastorno (Halperin, Berwid, \& O’Neill, 2014).

La evidencia sobre estudios que utilizaron neuroimágenes, epidemiología genética y tratamiento farmacológico sugiere que los neurotransmisores tienen un rol importante en el TDAH. Los neurotransmisores son sustancias químicas creadas en las células nerviosas (neuronas) que transportan información de una célula a otra por medio del espacio sináptico. Para que la transmisión de información en el espacio sináptico sea exitosa, es necesario que las neuronas que recibirán la información posean los receptores apropiados. Usualmente, el sistema de recompensa del cerebro humano depende del neurotransmisor llamado dopamina para lograr la comunicación entre neuronas (Volkow et al., 2009). La dopamina es segregada cuando surge un estado de recompensa en el cerebro y está relacionada positivamente con la motivación y recompensa (Volkow et al., 2009). Algunos estudios transversales apuntan a que el TDAH está correlacionado con polimorfismos genéticos, los cuales afectan la función del transportador de dopamina (DAT1) en el cuerpo estriado (Jeong et al., 2015) y las funciones del receptor de dopamina (DRD4) en la corteza prefrontal (Swanson et al., 1998). En ambos casos, los polimorfismos relacionados a la disfunción del transportador y/o receptor de dopamina resultan en una disminución en la concentración de neurotransmisores (Diamond, 2007). Ensayos clínicos que utilizaron tratamientos farmacológicos (metilfenidato o la anfetamina) revelaron que los niños con TDAH se benefician de estos (Jensen et al., 2001). Específicamente, el metilfenidato se encarga de inhibir el transportador de dopamina (DAT por sus siglas en inglés) (Volkow, Wang, Fowler, \& Ding, 2005), el cual es responsable de remover la dopamina y norepinefrina del espacio 
sináptico; mientras que la anfetamina aumenta la liberación de dopamina y norepinefrina (Diamond, 2007). Algunos estudios que utilizaron neuroimágenes evidencian la desregulación en los neurotransmisores. Los investigadores reportaron que los niños con TDAH presentan niveles más bajos de dopamina en el espacio sináptico (Volkow et al., 2009), hipo-excitabilidad neuronal en reposo (Barry, Clarke, Johnstone, McCarthy, \& Selikowitz, 2009) e hipo-activación de la red relacionada al funcionamiento ejecutivo (FE) y atención (Cortese et al., 2012), en comparación con los niños aparentemente saludables. El FE es un concepto que abarca una amplia gama de funciones cognitivas necesarias para el razonamiento, solución de problemas, planificación, organización y ejecución de la conducta (Diamond \& Lee, 2011). Un meta-análisis reveló que los niños con TDAH $(\mathrm{N}=6,703)$ obtuvieron puntuaciones significativamente adversas en un examen neuropsicológico sobre el FE (tareas que incluyen la solución de laberintos, crucigramas y rompe cabezas) comparadas con las puntuaciones de los niños aparentemente saludables aun después de controlar por variables concomitantes relevantes (Willcutt, Doyle, Nigg, Faraone, \& Pennington, 2005).

La actividad física (AF) se refiere a todo movimiento del cuerpo producido por los músculos esqueléticos que sobrepasa el gasto energético en reposo (Caspersen, Powell, \& Christenson, 1985). En cambio, el ejercicio se refiere al tipo de AF que se realiza con el objetivo de mejorar algún aspecto en específico de la salud o el rendimiento (Caspersen et al., 1985). Participar regularmente en AF y ejercicio produce mejoras a la salud y aptitud física (ej. fortaleza) al igual que brinda beneficios neurocognitivos y psicológicos (Piercy et al., 2018). El interés inicial por estudios sobre ejercicio, AF y aptitud física en niños con TDAH surgió de observaciones sobre déficits neurocognitivos asociados con el TDAH y beneficios neurocognitivos que brinda la AF en poblaciones sin TDAH (especialmente el FE y aumentos en los niveles de neurotransmisores en la sangre) (Halperin et al., 2014). En adultos, la AF aeróbica aumenta el flujo sanguíneo en el área cortical (Ogoh \& Ainslie, 2009) y la segregación de neurotransmisores; y a su vez, estos cambios están relacionados con aumentos en la excitabilidad y mejoras en el desempeño cognitivo (Davey, 1972).

Estudios sobre AF aeróbica de corta duración en niños aparentemente saludables demostraron un gran aumento en los niveles de neurotransmisores, velocidad de procesamiento cognitivo y control inhibitorio luego de haber realizado ejercicio de corta duración; sin embargo, estos beneficios no son evidentes en tareas cognitivas más complejas (ej. planificación, cambio de tarea) (Verburgh, Königs, Scherder, \& Oosterlaan, 2014). Por consiguiente, la evidencia sugiere que los efectos del ejercicio aeróbico de intensidad moderada y de corta duración incluyen la mejora de la concentración, la atención y el desempeño en ciertas tareas por medio de cambios transitorios; sin embargo, una sola sesión de AF de corta duración no se considera suficiente para alterar la trayectoria del desarrollo neural o de sostener los cambios por un periodo prolongado. En cuanto a los beneficios del desarrollo neuronal a largo plazo, los estudios sobre intervenciones de varias semanas ( 3 a 9 meses) han demostrado beneficios en la función neurocognitiva en niños clasificados en peso saludable (Hillman et al., 2014), y en sobrepeso y obesos (Davis et al., 2011). Algunos hallazgos significativos incluyen alteraciones en la actividad cerebral (evaluados con electroencefalograma (EEG) (Hillman et al., 2014) e imagen de resonancia magnética funcional (Davis et al., 2011)), integridad de la materia blanca (evaluada 
con imágenes de tensor de difusión (Schaeffer et al., 2014), tareas neuropsicológicas del FE (Davis et al., 2011; Hillman et al., 2014) y desempeño en matemáticas (Davis et al., 2011).

La evidencia científica en aumento investiga las relaciones entre AF, así como los conceptos relacionados como coordinación motora, aptitud física y participación en deportes, y el funcionamiento neurocognitivo, del comportamiento y académico de niños con TDAH o en el espectro de TDAH. Esta revisión de literatura cualitativa pretende proveer una visión general sobre: (1) estudios observacionales de AF y el TDAH en diferentes etapas del desarrollo humano; (2) experimentos que evalúan los efectos agudos de la AF en niños y niñas con TDAH; y (3) experimentos y estudios observacionales que evalúan los efectos crónicos del ejercicio en niños y niñas con TDAH.

\section{Estudios Observacionales Sobre AF y el TDAH en DifERENTES Etapas del DesarRollo HUMANO}

Por definición. Los niños con TDAH son más "hiperactivos" que los niños aparentemente saludables; por consiguiente, se tiende a asumir que también poseen altos niveles de coordinación, aptitud física y AF. Sin embargo, los niños con TDAH sin tratamiento farmacológico son $40 \%$ más propensos [así como los adultos con TDAH son $70 \%$ más propensos] a ser obesos, comparados con los niños aparentemente saludables (Cortese \& Tessari, 2017). Dos estudios longitudinales demostraron que entre $34 \%$ y $41 \%$ de los niños con TADH se convierten en adultos obesos comparado con individuos aparentemente saludables, de los cuales solo entre $22 \%$ y $25 \%$ se convierten en adultos obesos (Castaneda et al., 2016; Cortese et al., 2013). Esta realidad contradictoria sugiere posibles diferencias en la trayectoria de los estilos de vida a lo largo de las etapas de desarrollo. Desafortunadamente, se desconoce de algún estudio longitudinal que compare AF en niños o niñas con TDAH versus niños o niñas aparentemente saludables durante el transcurso de su desarrollo. No obstante, una síntesis de estudios transversales a través de las etapas de desarrollo puede brindar información para formular hipótesis preliminares que han de ser evaluadas en un futuro.

\section{ESTUDIOS DURANTE LA NIÑEZ TEMPRANA (4-6 AÑOS)}

Hasta la fecha, dos estudios transversales han investigado las relaciones entre la AF evaluada a través de la acelerometría e inatención e hiperactividad reportados por maestros o padres. En el primer estudio se evaluaron 450 niños y niñas pre-escolares que no recibían tratamiento farmacológico y se encontró que las puntaciones más altas en hiperactividad/inatención están relacionadas con un bajo porcentaje de grasa corporal y con niveles altos de AF y tiempo sedentario (Ebenegger et al., 2012). Sin embargo, los autores también reportaron que la puntuación de hiperactividad/inatención también estaba positivamente relacionada con tiempo excesivo viendo televisión y con hábitos alimenticios pobres. En el segundo estudio evaluaron la AF con acelerómetros en 247 niños y niñas pre-escolares y similarmente, los autores encontraron que los altos niveles de AF de intensidad moderada (AFMV) están asociados con los síntomas de la conducta externa (McNeill, Howard, Vella, Santos, \& Cliff, 2018). Estos hallazgos preliminares sugieren que la impulsividad e hiperactividad que caracteriza el TDAH brinda beneficios por medio de la promoción de AFMV durante un periodo en el cual la AF es mayormente realizada en forma de juego libre y desestructurada. Sin embargo, estas características pueden hacer que los niños estén más susceptibles a actividades altamente placenteras y obesogénicas. Dado que los niños con TDAH participan de más AFMV durante la niñez temprana, también se especula observar ventajas en los niveles de aptitud física. No obstante, un estudio comparó seis pruebas de aptitud física durante el periodo de preintervención entre 18 niños y niñas pre-escolares que fueron clasificados en el $5 \%$ más alto de 
los síntomas del TDAH y 18 niños y niñas de la misma edad, pero que fueron clasificados en el $5 \%$ más bajo de los síntomas del TDAH. Los autores revelaron que los niños que formaban parte del grupo de síntomas del TDAH bajo presentaron mejor desempeño (aunque no fue estadísticamente significativo) en las pruebas de aptitud física (ej. 50 abdominales más en 60 segundos y un promedio de $60 \mathrm{~cm}$ más en la prueba de flexión de tronco sentado en comparación con los niños en el grupo de los síntomas del TDAH más alto) (Golubović, Milutinović, \& Golubović, 2014).

\section{ESTUDIOS DURANTE LA NIÑEZ MEDIA Y TARDÍA (7-12 AÑOS)}

Durante la niñez media y tardía, la evidencia preliminar sugiere que los niños con TDAH permanecen más [o similarmente] físicamente activos, pero otras disparidades alarmantes surgen e incluyen bajo desempeño en las destrezas fundamentales de movimiento, niveles bajos en aptitud física y menos participación en deportes organizados. Un estudio transversal pequeño realizado en Taiwán les administró acelerómetros durante 7 días a 20 niños en escuela elemental con TDAH y a 20 niños de la misma edad y aparentemente saludables. Los investigadores encontraron altos niveles de AF en el grupo de niños con TDAH comparado con los niños aparentemente saludables (Lin, Yang, \& Su, 2013). Un análisis post hoc que evaluó cada hora reveló que los niños con TDAH participaron de más AF durante periodos desestructurados a pesar de que presentaron niveles bajos de AF durante los periodos estructurados. Este hallazgo provee evidencia de que los niños con TDAH son más activos durante esta etapa del desarrollo debido a la hiperactividad durante el juego libre. Los análisis de los datos del 2003 - 2004 sobre la Encuesta Nacional de Examen de Salud y Nutrición (NHANES por sus siglas en inglés) sustentan estas disparidades. Al comparar 188 niños y niñas diagnosticados con el TDAH entre las edades de 6 a 17 años con 2,325 niños y niñas aparentemente saludables, se encontró que los niños diagnosticados con el TDAH participaron significativamente de más AFMV (promedio = 59.9 vs promedio $=51.7 \mathrm{~min} /$ día) que los niños aparentemente saludables. Además, los niños con el TDAH estuvieron más propensos a cumplir la recomendación estadounidense de AF-la cual establece que los niños deben de acumular al menos 60 minutos de AFMV diariamente(45\% vs $35 \%$ ). Además, los niños con el TDAH presentaron menos minutos en tiempo sedentario evaluado con acelerómetros (promedio $=416$ vs promedio $=435$ minutos $/$ día). El estatus de diagnóstico permaneció como un predictor significativo aun después de controlar por raza/etnicidad, género, ingreso familiar y edad (Ramer, Hawkins, Hilgenkamp, SantiagoRodríguez, \& Bustamante, 2019).

En cambio, varios estudios transversales consistentemente demuestran destrezas fundamentales de movimiento deficientes en niños y niñas con el TDAH, relativo a los niños y niñas aparentemente saludables; más de la mitad de los niños con el TDAH presentan problemas en la coordinación motora (Harvey et al., 2009; Kaiser, Schoemaker, Albaret, \& Geuze, 2015). Las destrezas fundamentales de movimiento se refieren a un número reducido de movimientos básicos y necesarios que al ser combinados forman movimientos más complejos y especializados, los cuales se requieren para participar de actividades y juegos físicamente activos. Algunos estudios longitudinales indican que dominar las destrezas fundamentales de movimiento durante etapas tempranas en el desarrollo humano predice la AF en etapas tardías (Lubans, Morgan, Cliff, Barnett, \& Okely, 2010). Dos estudios sugieren que la inatención en los niños con el TDAH puede prevenir que participen de actividades estructuradas que fomentan el desarrollo de estas destrezas. El primer estudio demostró que las destrezas fundamentales de movimiento están inversamente relacionadas con la severidad de la inatención, pero no con la severidad de la hiperactividad (Fenollar-Cortés, Gallego-Martínez, \& Fuentes, 2017; Fliers et al., 2008). El segundo estudio, una revisión de literatura sistemática que incluyó 45 artículos científicos, reveló que entre una cuarta a dos terceras partes de los niños con el TDAH que están 
bajo tratamiento farmacológico lograron obtener niveles de coordinación motora iguales a los niños aparentemente saludables (Kaiser et al., 2015); posiblemente esto se debe a que el medicamento aumenta la atención y por consiguiente, la participación en las actividades que retan las destrezas de movimiento.

Otros estudios sobre la niñez media y tardía también sugieren peores niveles de aptitud física en niños y niñas con el TDAH o ninguna diferencia por estatus de diagnóstico. Un estudio con 947 niños y niñas con edades entre 11 y 14 años, comparó las vueltas completadas en la carrera progresiva de capacidad cardiovascular (PACER por sus siglas en inglés) entre los niños con el TDAH y los niños aparentemente saludable. Esta prueba evalúa la capacidad aeróbica y requiere que cada niño o niña corra de un extremo a otro (20 metros) de forma continua y progresiva ya que el tempo para completar cada vuelta aumenta. La cantidad de vueltas completadas por cada niño es su puntuación y los clasifica dentro de la zona saludable para la aptitud física o la zona insalubre para la aptitud física de acuerdo a su edad y género. El estudio reportó que los niños con el TDAH completaron 24 vueltas, cinco vueltas menos que los niños aparentemente saludable (Martinson et al., 2018). Estudios con menos participantes presentaron resultados contradictorios, pero ninguno sugiere ventajas en los niveles de aptitud física para los niños con TDAH. Un estudio con niños y niñas taiwaneses ( $\mathrm{N}=36$, entre 7 a 14 años) encontró que los niños con el TDAH completaron 20 vueltas en el PACER comparado con los niños aparentemente saludables, los cuales completaron 22 vueltas (Pan et al., 2017). Un estudio de intervención en niños y niñas afroamericanos con TDAH o con trastorno de conducta disruptiva ( $N=35$, entre 6 a 12 años), evidenció que la mitad de los niños fueron clasificados por FitnessGram como "necesita mejorar" mientras que la otra mitad fue clasificada como "necesita mejorar-riesgo a la salud" (Bustamante et al., 2016). Por último, en una muestra de 70 niños (edad promedio $=9.7 \pm 1.3$ años), los investigadores no encontraron diferencia en aptitud física entre los niños con TDAH bajo tratamiento farmacológico, niños con TDAH sin tratamiento farmacológico, y niños aparentemente saludables (Verret, Gardiner, \& Béliveau, 2010).

Una tercera área de investigación durante la niñez intermedia y tardía está relacionada con la participación en programas de AF estructurada. Los programas estructurados (ej. deportes en equipo) pueden ser especialmente beneficiosos para niños con el TDAH porque retan el FE, refuerzan las reglas y rutinas en los niños y exhiben conductas prosociales (Diamond \& Lee, 2011). Un estudio transversal reciente reveló que los niños con TDAH que participan en deportes organizados presentan menos síntomas relacionados al trastorno que aquellos niños con TDAH que no participan en deportes (Watson, Timperio, Brown, Hinkley, \& Hesketh, 2019). Desafortunadamente, las mismas características que hacen estos programas beneficiosos cognitivamente son las que los hacen menos divertidos para los niños con TDAH. Un par de estudios cualitativos revelaron que los niños con TDAH (entre 8 a 12 años) reportaron menos diversión y participación en programas de AF estructurada, más sentimientos negativos hacia la AF estructurada y una mayor preferencia por jugar con sus amigos (Harvey et al., 2009; Shimoni, Engel-Yeger, \& Tirosh, 2010). En un estudio sobre la participación de programas después de la escuela en niños y niñas afroamericanos con TDAH o con trastorno de conducta disruptiva $(\mathrm{N}=$ 175) que asistían a la escuela elemental, se encontró que la mitad de los padres (54\%) reportaron que sus hijos participaban de programación supervisada después de la escuela $\geq 2$ días/semana. Sin embargo, la participación en programas sedentarios (ej. tutorías, educación religiosa) excedió la participación en programas de AF (ej. programación en los parques recreativos, Asociación Cristiana de Jóvenes (YMCA por sus siglas en inglés)) por $83 \%$; mientras que solo un 10\% de los niños participó $\geq 2$ días/semana de deportes. Esto último indica una participación extremadamente baja (Bustamante, 2018). Por el contrario, entre un $25 \%$ a $29 \%$ de los niños y niñas en Estados Unidos participó regularmente de deportes competitivos (State of Play 2017: Trends and Developments, 2017). Esto es preocupante ya que apunta a que los niños y niñas 
con TDAH son desproporcionalmente marginados de participar de programas de AF porque en estos tipos de programas, a medida que avanza la edad, también la estructura, las exigencias y la selectividad son más rigurosas. Se sugiere realizar estudios con muestras representativas a nivel nacional para probar esta hipótesis.

\section{ESTUDIOS DURANTE LA ADOLESCENCIA (13-19 AÑOS)}

Al llegar a la adolescencia cualquier ventaja durante la niñez en AF y tiempo sedentario asociada con el TDAH desaparece o es revertida. Un análisis con datos entre los años 2001 y 2004 de la Encuesta Nacional de Examen de Salud y Nutrición no reportó diferencias en AF entre jóvenes entre 12 a 15 años con el TDAH $(\mathrm{N}=199)$ y jóvenes aparentemente saludables $(\mathrm{N}=1,490)$ (Curtin, 2015). En cambio, un estudio estadounidense que evaluó a 45,897 niños, niñas y adolescentes entre las edades de 10 a 15 años reportó que los adolescentes con el TDAH sin tratamiento farmacológico eran $76 \%$ más propensos a reportar que cumplían con la recomendación de AF y $120 \%$ más propensos a exceder la recomendación de tiempo sedentario comparado con sus pares aparentemente saludables (Cook, Li, \& Heinrich, 2015). Finalmente, un estudio de cohorte prospectivo en Australia evaluó 2,868 recién nacidos y reveló que cuando los niños con el TDAH cumplieron 14 años estaban 53\% menos propensos que los adolescentes de 14 años aparentemente saludables a hacer ejercicio 5 a 6 veces por semana y $67 \%$ menos propensos a hacer ejercicio $\geq 7$ veces por semana (Howard et al., 2011).

\section{Evidencia sobre Efectos Neurocognitivos Transitorios de la AF de CoRTA DuRAción en NIÑOS CON TDAH}

El primer estudio sobre el impacto del ejercicio de corta duración en el desempeño cognitivo en niños o niñas con TDAH fue publicado en 1983, poco tiempo después que el trastorno fuera llamado TDAH por la Asociación Psicológica Americana en 1980. Los investigadores probaron la hipótesis de que el desempeño cognitivo sería optimizado por una excitación moderada que concuerda con la presencia adecuada, pero no excesiva, de los niveles de dopamina a nivel extracelular (conocido como la hipótesis de la $U$ invertida). Los autores esperaban que la duración adecuada para optimizar la excitación sería diferente para los niños con el TDAH $(\mathrm{N}=$ 31) en comparación con sus pares aparentemente saludables $(N=31)$ (Craft, 1983). Los niños fueron evaluados durante 4 visitas separadas, en cada visita pedalearon por 0, 1, 5015 minutos (el tiempo durante el cual pedalearon fue asignado aleatoriamente). Los niños pedalearon hasta permanecer en una frecuencia cardiaca $170 \mathrm{lpm}$ e inmediatamente después de completar cada periodo de ejercicio completaron una prueba de memoria funcional. Los autores no encontraron diferencias en la memoria funcional por la duración del ejercicio o entre días donde se ejercitaron y días en los que no se ejercitaron.

Veinte años más tarde, dos estudios con un diseño de medidas repetidas evaluaron los efectos del ejercicio de corta duración en la función de los neurotransmisores en niños con TDAH. El primer estudio recolectó medidas que representan la concentración de dopamina en niños con TDAH $(\mathrm{N}=18)$ antes y después de permanecer en descanso, realizar una caminata de corta duración y de intensidad moderada o vigorosa en la cinta rodante (Tantillo, Kesick, Hynd, \& Dishman, 2002). Los análisis realizados de la intensidad de la AF (moderada vs vigorosa vs descanso) por tiempo (pre-intervención vs post-intervención) no fueron significativos. Sin embargo, un análisis post hoc de subgrupos reveló que solo los niños con el TDAH tenían niveles más altos de dopamina después de realizar ejercicio vigoroso, mientras que las niñas con TDAH presentaron niveles más altos de dopamina después de realizar ejercicio moderado. En el segundo estudio, los investigadores evaluaron los efectos de 20 minutos de ejercicio vigoroso en cicloergómetro en los niveles de neurotransmisores periféricos en niños y niñas con TDAH ( $N=$ 
10) y pares aparentemente saludable $(N=8)$ (Wigal et al., 2003). Los niños pedalearon a una intensidad moderada a vigorosa en la cual la frecuencia cardiaca más alta reportada en el grupo de los niños con TDAH fue 178 lpm mientras que en el grupo de los niños aparentemente saludables fue de $189 \mathrm{lpm}$. En cada sesión de ejercicio los participantes realizaron 10 series consecutivas que consistieron en 2 minutos de intensidad moderada a vigorosa seguidos de 1 minuto de descanso. Las muestras de sangre se obtuvieron antes, durante los últimos 2 minutos del ejercicio, 30 minutos después del ejercicio y 60 minutos después del ejercicio. En ambos grupos, los niveles de transmisores aumentaron dramáticamente durante ejercicio, permanecieron relativamente elevados justo después del ejercicio y regresaron a los niveles de pre-intervención 30 minutos después del ejercicio. Los autores observaron una reducción mínima y significativa en los niveles de neurotransmisores en sangre durante el ejercicio para los niños con TDAH relativo a sus pares aparentemente saludables, pero esto es difícil de explicar por la diferencia en la frecuencia cardíaca máxima observada entre los grupos. Estos hallazgos generan preguntas sobre si los niños con TDAH pueden obtener mayores beneficios del ejercicio debido a niveles bajos de excitación, menor cantidad de neurotransmisores en sangre 0 simplemente ninguna diferencia en respuesta al ejercicio.

Estudios más sofisticados se concentraron en evaluar la función cerebral y el desempeño durante tareas neuropsicológicas, lo que produjo un cambio en enfoque, dejando a un lado las variables primarias relacionadas a mecanismos. Estos estudios pueden ser categorizados como investigaciones sobre: (1) el efecto del estatus del diagnóstico (TDAH vs aparentemente saludable) en el ejercicio, (2) el efecto del ejercicio vs actividades sedentarias en niños con TDAH y (3) diferencias en el efecto de la AF por estatus del diagnóstico.

En la primera categoría, dos estudios evaluaron la interacción de 2 vías entre el tiempo (preintervención vs post-intervención) y diagnóstico (TDAH vs aparentemente saludable). Ninguno de los dos estudios reveló una diferencia en la respuesta del ejercicio por estatus de diagnóstico en el análisis de interacción de 2 vías; sin embargo, en análisis post hoc se observaron hallazgos contradictorios en los resultados dentro de los grupos (este es el efecto del tiempo solamente independiente de cualquier comparación por grupo). Específicamente, Mahon y colegas (2013) reportaron que los niños con el TDAH $(N=21)$ bajo tratamiento farmacológico mostraron un rendimiento significativamente peor en las tareas cognitivas después del ejercicio, mientras que Gapin y colegas $(\underline{2015})$ reportaron mejoras significativas $(d=0.82)$ después de realizar ejercicio en estudiantes universitarios con el TDAH $(N=10)$. Estos resultados contradictorios pueden reflejar diferencias en el diseño de los estudios. Gapin y colegas (2015) utilizaron AF de intensidad moderada (entre $50 \%$ a $65 \%$ de la frecuencia cardíaca de reserva), mientras que Mahon y colegas $(\underline{2013})$ utilizaron un protocolo más intenso (90\% del VO2 pico durante 20 minutos o una frecuencia cardíaca pico de 200lpm) y administraron pruebas cognitivas inmediatamente después de realizar ejercicio sin brindar el periodo convencional de descanso de $\sim 15$ a 30 minutos para que la frecuencia cardíaca regrese a niveles dentro de $\sim 10 \%$ de los niveles de descaso (Pontifex, Saliba, Raine, Picchietti, \& Hillman, 2013). Los resultados de ambos estudios refuerzan la hipótesis inicial de la $U$ invertida, pero relacionada a intensidad en vez de a la duración (Craft, 1983) de tal forma que el ejercicio vigoroso sin descanso puede perjudicar temporalmente la cognición, especialmente en ausencia de descanso.

En la segunda categoría, los estudios evaluaron la interacción de 2 vías entre la AF (ejercicio vs. Sedentarismo) y el tiempo (pre-intervención vs post-intervención) en niños con TDAH únicamente. Dos estudios utilizaron un protocolo de 20 minutos corriendo en la cinta rodante a una intensidad moderada (frecuencia cardíaca entre 150 a $170 \mathrm{lpm}$ ) precedidos por 5 minutos de calentamiento y seguidos por otros 5 minutos de vuelta a la calma. Ambos estudios revelaron mejoras significativas en la cognición después de realizar ejercicio; mientras que después de 
hacer actividades sedentarias observaron mejoras significativas en tiempo de reacción e inhibición (Chuang, Tsai, Chang, Huang, \& Hung, 2015; Medina et al., 2010). Adicionalmente, Chuang y colegas (2015) realizaron encefalogramas los cuales revelaron alteraciones neurológicas y significativas en los procesos de atención y preparación durante las tareas realizadas después del ejercicio. Un tercer estudio asignó aleatoriamente 46 niños y niñas entre 8 y 12 años de edad, a 15 minutos de AFMV con video juegos (frecuencia cardíaca promedio = 148 lpm) o ver un documental breve. Los niños asignados al grupo de AFMV aumentaron significativamente su velocidad de ejecución de las tareas neurocognitivas de FE comparados al grupo control, pero no fueron significativamente más certeros en sus contestaciones (Benzing, Chang, \& Schmidt, 2018).

Por último, 3 estudios evaluaron la interacción de 3 vías entre tiempo (pre-intervención vs postintervención), actividad (ejercicio vs sedentarismo) y estatus por diagnóstico (TDAH vs aparentemente saludable). Ninguno de estos estudios evidenció diferencias en las respuestas neurocognitivas entre el tipo de actividad por estatus del diagnóstico (no hubo interacción usando 3 vías). Sin embargo, los 3 estudios agruparon a los niños por tipo de diagnóstico y reportaron diferencias significativas, con un tamaño del efecto moderado a grande, para la interacción de 2 vías entre tiempo (pre-ejercicio vs post-ejercicio) y actividad (ejercicio vs actividad sedentaria) en la asignación de recursos atencionales medidos a través de encefalogramas, velocidad de respuesta e inhibición durante tareas neuropsicológicas (Ludyga et al., 2017; Piepmeier et al., 2015; Pontifex et al., 2013). Pontifex y colegas (2013) también reportaron un tamaño del efecto grande para la interacción de 2 vías entre tiempo y actividad en evaluaciones directas de matemáticas $(d=1.25)$ y comprensión de lectura $(d=1.58)$.

En conjunto, esta evidencia basada en experimentos realizados en laboratorios sugiere que el ejercicio aeróbico de corta duración [relativo a actividades sedentarias] mejora la inhibición, atención prolongada y procesos neurológicos en niños o niñas con TDAH durante periodos de tiempo pasajeros después de realizar ejercicio de corta duración. Sin embargo, no existe evidencia de diferencias en las variables antes mencionadas según el diagnóstico. Los hallazgos son prometedores, pero deben interpretarse con cuidado ya que no garantizan que se puedan generalizar fuera del laboratorio, donde el control es excesivo (tipo de ejercicio, duración e intensidad), el lugar donde se realizan las pruebas neuropsicológicas no cuenta con distracciones ((ej. Salones a pruebas de sonidos) y hay excelente supervisión (los investigadores ofrecen una relación de 1:1 en atención y motivación). La prioridad de lograr validez interna sacrifica la validez externa. Los niños y niñas con TDAH están más propensos a desempeñarse al máximo en las pruebas neuropsicológicas cuando están bajo condiciones controladas; pero, el salón de clases es diferente porque existen muchas distracciones como los payasos del salón, niños o niñas que intimidan a otros (matonismo), chismes e intereses románticos. En el laboratorio, los beneficios de concentración resultantes del ejercicio pueden ser aplicados al desempeño de tareas relacionadas al FE, pero en el salón de clases no hay garantía de que las mejoras en la concentración se apliquen al contenido de la clase; por el contrario, puede que sean aplicadas a crear la broma perfecta que generará discordia en el salón de clase.

Afortunadamente, algunos estudios han investigado el efecto de pausas activas en la conducta dentro del salón de clases. Un estudio examinó el efecto de las pausas activas de diferentes duraciones (5, 10 y 20 minutos) en el salón de clase en niños y niñas cursando el cuarto y quinto grado en comparación con pausas pasivas (Howie, Beets, \& Pate, 2014). El mejoramiento más evidente $(10 \%)$ en el comportamiento relacionado a las tareas que debían realizar los niños durante la clase (comportamiento esperado) se observó después de las pausas activas de 10 minutos y un mayor mejoramiento $(30 \%)$ para los estudiantes que inicialmente obtuvieron una puntuación más baja en el comportamiento esperado. Estos hallazgos sustentan estudios previos 
en los cuales los participantes realizaron 10 minutos de pausa activa aeróbica y demostraron un mejoramiento promedio de $8 \%$ en el comportamiento esperado comparado con días en los cuales no tuvieron pausas activas; y más aún, un mejoramiento de $20 \%$ para aquellos niños que obtuvieron inicialmente una puntuación más baja en comportamiento esperado (Mahar et al., $\underline{2006}$ ). Específicamente relacionada al TDAH, Ridgway y colegas (2003) utilizaron un diseño de caso único para investigar el efecto de 10 minutos de juego libre durante el receso a las 9:45 am en el comportamiento del salón de clases de 3 niños con TDAH y 3 niños aparentemente saludables que cursaban el segundo grado (Ridgway, Northup, Pellegrin, LaRue, \& Hightsoe, 2003). Observaciones sistemáticas desde las 8:30 am hasta las 10:30 am en días con y sin receso revelaron que las conductas disruptivas aumentaron linealmente a través del tiempo que los niños permanecieron sentados en el salón de clases, especialmente en los días que no tuvieron receso. Por ejemplo, los autores reportaron que el comportamiento inapropiado de los niños era casi el doble a las 10:30 am comparado con las 8:30am. Los resultados indican que la sincronización puede ser importante para maximizar los beneficios de la AF de corta duración para los estudiantes con TDAH. Estos hallazgos junto con el resto de la evidencia científica sugieren que las pausas activas brindan beneficios a la aptitud física, cognición y auto estima, los cuales han convencido a los investigadores y profesionales relacionados con la educación a abogar por la integración de AF a lo largo del día escolar, especialmente en los niños y niñas con TDAH (Lewallen, Hunt, Potts-Datema, Zaza, \& Giles, 2015; Mulrine, Prater, \& Jenkins, 2008). Por lo tanto, la literatura sobre AF de corta duración brinda evidencia contundente para la integración de AF en las rutinas del diario vivir de niños y niñas con el TDAH para optimizar el funcionamiento; sin embargo, la literatura no brinda percepciones sobre como la AF diaria altera al desarrollo neurológico. Para estos estudios longitudinales y de intervenciones de varias semanas es necesario realizar ensayos clínicos.

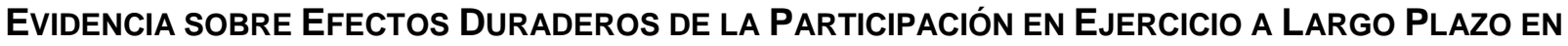 EL DESARROLlo NEUROLÓgico EN NiÑOS Y NiÑAS CON EL TDAH}

Dos estudios longitudinales y recientes sugieren que el FE esta genéticamente determinado por alrededor de 79 a 100\% (Engelhardt, Briley, Mann, Harden, \& Tucker-Drob, 2015; Friedman \& Miyake, 2017; Friedman et al., 2008). Estos factores heredados concuerdan con los resultados de alta heredabilidad del propio TDAH y brindan apoyo adicional a la importancia genética de las estructuras y funciones neurobiológicas que determinan el FE y el TDAH (Friedman \& Miyake, 2017). Por ejemplo, la integridad de la materia blanca es altamente heredable (hasta un $80 \%$ ), pero estudios con gemelos sugieren que el estatus socioeconómico interactúa con la herencia de las fibras de la integridad de la materia blanca de tal forma que la heredabilidad es baja en individuos con un trasfondo socioeconómico bajo (Chiang et al., 2011). Entre los individuos con un bajo nivel de coeficiente intelectual, la genética aporta solo un $40 \%$ de la variabilidad en la anisotropía fraccional (Chiang et al., 2011). Es importante señalar que la alta heredabilidad no implica que una característica no es modificable, sino que la heredabilidad se refiere a la cantidad de diferencias que pueden ser explicadas genéticamente a través de estudios observacionales. Sin embargo, las intervenciones que manipulan factores no relacionados a la genética (p. ej. Estilos de vida, ambiente físico y social) muestran que los niños/as con TDAH mejoran significativamente el FE al igual que los niños/as aparentemente saludables; por consiguiente, aunque todos mejoran, aún existe una diferencia marcada en el FE entre los niños/as con el TDAH y sus pares aparentemente saludables. Por lo tanto, existe espacio para que factores ambientales tengan efecto en las características neurocognitivas, especialmente durante el desarrollo, lo que provoca un aumento en las publicaciones relacionadas con la evaluación del efecto de la AF en esas características en niños y niñas con TDAH. 
Actividad Física y TDAH

\section{EVIDENCIA DE ESTUDIOS OBSERVACIONALES}

En un estudio transversal, Gapin y Etnier (2010) proveyeron acelerómetros justo después de completar las tareas neuropsicológicas durante 7 días consecutivos a 18 niños con TDAH. La AFMV se asoció con mejoras en el desempeño en planificación, pero no en inhibición o memoria funcional (Gapin \& Etnier, 2010). Es importante señalar que los estudios transversales no pueden determinar causalidad. En cambio, los diseños longitudinales evalúan el orden en el cual ocurren los eventos, por consiguiente, brindan direccionalidad. En un estudio que incluyó 8,106 niños y niñas australianos, los investigadores los evaluaron desde el nacimiento y encontraron que la inactividad física a los 8 años de edad predice la severidad de la inatención a los 16 años de edad; también, encontraron que los síntomas del TDAH a los 8 años de edad predicen obesidad e inactividad a la edad de 16 años (Khalife et al., 2014). En un estudio realizado en Suecia con 232 gemelos idénticos, los investigadores pidieron que los gemelos reportaran sus niveles de AF cuando tenían 16 a 17 años y 3 años más tarde los padres reportaron los síntomas del TDAH cuando los gemelos tenían entre 19 a 20 años. Los investigadores encontraron que una mayor participación en AF durante la adolescencia predice menos síntomas del TDAH en la adultez temprana (Rommel et al., 2015), lo que sugiere beneficios duraderos de la AF en el desarrollo neurológico aún durante la adolescencia tardía.

\section{EVIDENCIA DE ESTUDIOS DE INTERVENCIONES DE VARIAS SEMANAS}

Por definición, los estudios sobre AF crónica son considerados longitudinales (duran varias semanas a meses) y por consiguiente permiten evaluar cambios en el comportamiento, como síntomas y disfunción, el cual es más importante para los padres, educadores y elaboradores de política pública. Para ejemplificar esta área de investigación se encuentra el trabajo del Dr. Jeffrey M. Halperin, un neurocientífico del desarrollo en la Universidad de la Ciudad de Nueva York. El Dr. Halperin desarrolló un programa de AF para niños y niñas con TDAH llamado Entrenamiento de Destrezas Ejecutivas, de Atención y Motoras (TEAMS por sus siglas en inglés) (Halperin et al., 2013). El programa TEAMS entrena a los padres para que puedan hacer que sus niños/as entre las edades de 3 a 5 años con el TDAH participen de juegos físicamente activos durante 30 a 45 minutos (Halperin \& Healey, 2011). El elemento más importante del programa es la sincronización. Una intervención de $\mathrm{AF}$ durante la niñez temprana puede ser más beneficiosa que una intervención equivalente más tarde en el desarrollo. Esto es semejante a lanzar una pelota al aire, pues el más pequeño cambio en el ángulo durante la primera fase del lanzamiento puede alterar la trayectoria de la pelota. Actualmente, este estudio se está llevando a cabo, pero los resultados de un ensayo clínico abierto sugieren mejoras en la severidad de los síntomas después de 3 meses de haber finalizado la intervención (Halperin et al., 2013); no obstante, mantener rutinas de ejercicios por periodos más prolongados aun representa un reto.

Esta área de investigación verdaderamente ha recibido atención de forma desproporcionada debido al interés extremo en la capacidad de estas intervenciones de alterar las trayectorias neurológicas del desarrollo en personas con TDAH. Hasta la fecha, más de dos docenas de estudios han evaluado el efecto de intervenciones de AF durante varias semanas en niños o niñas con TDAH y desde el 2015 se han publicado múltiples revisiones de literatura sobre la influencia de las intervenciones de AF de varias semanas en la respuesta cognitiva y conductual en niños o niñas con TDAH [e.g., (Ash, Bowling, Davison, \& Garcia, 2017; Cerrillo-Urbina et al., 2015; Den Heijer et al., 2017; Neudecker, Mewes, Reimers, \& Woll, 2015; Ng, Ho, Chan, Yong, \& Yeo, 2017; Song, Lauseng, Lee, Nordstrom, \& Katch, 2016; Suarez-Manzano, Ruiz-Ariza, De La Torre-Cruz, \& Martinez-Lopez, 2018)]. Similarmente, varios meta análisis han sido publicados sobre la misma pregunta de investigación [e.g., (Tan, Pooley, \& Speelman, 2016; Vysniauske, Verburgh, Oosterlaan, \& Molendijk, 2016)]. Entre las revisiones de literatura, los autores han 
concluido que son evidentes los beneficios de los programas de AF aeróbica de intensidad moderada en la severidad de los síntomas, el FE y medidas de la salud física. Los meta análisis han estimado un tamaño del efecto (grupo $X$ tiempo) pequeño a moderado que varía entre Hedge $g=0.54$ (Vysniauske et al., 2016), $r=.181$ (Tan et al., 2016) y una diferencia de medias estandarizadas $=0.58$ (Cerrillo-Urbina et al., 2015) en el FE. Un meta análisis que incluyó a 249 niños/as con TDAH reportó un tamaño del efecto de moderado a grande en atención (diferencia de medias estandarizadas $=0.84$ ) e hiperactividad/impulsividad (diferencia de medias estandarizadas $=0.54$ ) (Cerrillo-Urbina et al., 2015). Desafortunadamente, cada meta análisis combinó en sus análisis estudios que brindaron ejercicios de corta duración con intervenciones de varias semanas, lo que limita las conclusiones. Más aun, varias revisiones de literatura han concluido que se necesitan más ensayos clínicos aleatorizados para confirmar los beneficios de la AF a largo plazo (Ng et al., 2017; Song et al., 2016; Suarez-Manzano et al., 2018).

Los ensayos clínicos aleatorizados son difíciles de llevar a cabo bajo cualquier condición, ya que tomar varias decisiones crea discrepancias en términos de los métodos y resultados; esto a su vez impide conclusiones definitivas. También, este tipo de estudio que incluye ejercicio durante varias semanas enfrenta los siguientes retos: los participantes son plenamente conscientes de la condición asignada, las familias se mudan, poco compromiso de parte de los participantes, dificultad para manejar un grupo con una gran cantidad de niños o niñas con TDAH, los adultos no completan algunas de las medidas porque están muy ocupados y hay dificultad para controlar las variables extrañas (Hoza, Martin, Pirog, \& Shoulberg, 2016). Dentro de las limitaciones metodológicas más comunes se encuentran la ausencia de un grupo control, asignación a los grupos no aleatorizada, potencia estadística inapropiada, ausencia de análisis por protocolo, no especificar previamente la variable de interés o primaria, las hipótesis o los análisis estadísticos que se van a realizar, análisis estadísticos que no concuerdan con el diseño del estudio, brindar actividades durante la intervención que son muy similares a la medida que se utilizará para evaluar la variable primaria, y no cumplir con los estándares o guías para reportar estudios que brindan una intervención (CONSORT, por sus siglas en inglés).

A pesar de estas limitaciones, se ha logrado recolectar suficiente evidencia para generar las siguientes hipótesis que ameritan ser probadas y que pueden ayudar a integrar el conocimiento obtenido en algo práctico.

Hipótesis 1: Los efectos de los estudios que brindan intervenciones de varias semanas disminuyen conforme los resultados se vuelven conceptualmente más distantes del estímulo.

La figura 1 muestra un mapa conceptual del impacto sobre el efecto de la AF en la función cerebral, cognición, comportamiento y desempeño académico en niños con TDAH. Los tamaños de efecto dentro del grupo (el efecto del tiempo independiente de la comparación) van de moderados a grandes en las pruebas neuropsicológicas y en el comportamiento reportado por los padres y maestros. Más aun, una mayor participación en un programa de AF está asociada con mayores beneficios derivados de estos resultados. Por ejemplo, un análisis secundario con datos de niños y niñas con TDAH y otros trastornos de conducta $(\mathrm{N}=103)$, que duró 7 semanas en las cuales participaron de ciclismo virtual, reveló que por cada 11 minutos que los niños o niñas participaban del ciclismo virtual se observó una disminución de 11 minutos en el periodo de castigo después de la escuela (Bowling et al., 2017). Los análisis de grupo X tiempo refuerzan estos hallazgos, ya que los estudios de intervenciones han reportado diferencias significativas entre los grupos en la función cerebral (Choi, Han, Kang, Jung, \& Renshaw, 2015), el FE EF (Kang, Choi, Kang, \& Han, 2011) y la severidad de los síntomas del TDAH (Hoza et al., 2015). Sin embargo, solo tenemos conocimiento de una intervención que reportó el efecto de la AF en el desempeño académico. Los autores reportaron un tamaño de efecto de pequeño a casi nulo 
entre grupos y dentro de éstos (Ramer, Davis, Frazier, Marquez, \& Bustamante, 2018). Se requiere de más investigaciones para probar esta hipótesis, pero la evidencia hasta el momento apunta a que mientras que el efecto de la AF dependerá de la variable de interés que se estudia, pero es lógico que mientras más se aleje la respuesta bajo estudio del estímulo inicial (AF), como se observa en la Fig. 1, más se debilitará la señal.

Figura 1. Mapa Conceptual de programas de AF de varias semanas y TDAH

\begin{tabular}{|c|c|c|c|c|c|}
\hline $\begin{array}{l}\text { Actividad } \\
\text { Física }\end{array}$ & $\begin{array}{l}\text { Función } \\
\text { Cerebral }\end{array}$ & $\begin{array}{l}\text { Función } \\
\text { Cognitiva }\end{array}$ & $\begin{array}{l}\text { Severidad de } \\
\text { los Síntomas }\end{array}$ & $\begin{array}{l}\text { Participación } \\
\text { Académica }\end{array}$ & $\begin{array}{l}\text { Desempeño } \\
\text { Académico }\end{array}$ \\
\hline
\end{tabular}

Hipótesis 2: Los beneficios de las intervenciones de AF de varias semanas dependen mayormente de la calidad de los programas juveniles sin importar el tipo de actividad realizada.

Los síntomas de inatención e hiperactividad que caracterizan el TDAH hacen que el manejo de grupos sea un mayor reto. Por lo tanto, la participación de niños o niñas con TDAH en AF requiere de estrategias para promover una participación proactiva y de manejo de conducta (reglas, rutinas, expectativas claras y consecuentes). Estos requisitos están extremadamente relacionados con los tratamientos psicológicos (basados en evidencia científica) para tratar el TDAH. La única forma de diferenciar los beneficios de programas que no incluyen AF de los beneficios de la AF exclusivamente es incluir un grupo control que reciba un programa sedentario. Al menos 3 estudios con niños y niñas con TDAH han utilizado este diseño y reportaron pocas diferencias significativas entre grupos, a pesar de las mejoras significativas reportadas en el grupo que recibió el programa de AF (Bustamante et al., 2016; Geladé et al., 2017; Hoza et al., 2015). Hoza y colegas (2015) realizaron el estudio más riguroso y con la mayor cantidad de niños y niñas con TDAH $(\mathrm{N}=94)$ hasta el momento. La literatura apunta a que cuando el grupo que recibió AF es comparado con grupos activos, entonces los tamaños de efecto en la severidad de los síntomas son de pequeños a casi nulo. Sin embargo, cuando el grupo que recibió AF es comparado con un grupo que no recibió AF, los tamaños de efecto son de moderados a grandes. Esta hipótesis también está sustentada por la variedad de formas en que se ofrece la AF, las cuales incluyen formato tradicional de la clase de educación física (Bustamante et al., 2016), correr distancias largas (Wendt, 2000), AF a través de video juegos (Benzing \& Schmidt, 2017), tenis de mesa (Pan et al., 2016), equitación (Pan et al., 2017), natación (Verret, Guay, Berthiaume, Gardiner, \& Béliveau, 2012), AF junto con psicología (Choi et al., 2015), yoga (Chou \& Huang, 2017) y ciclismo virtual (Bowling et al., 2017), entre otros. De ser cierto que las características más importantes de los programas de AF para mejorar el comportamiento de niñosy niñas con TDAH son aquellas asociadas con el ambiente en el cual se ofrece la AF, entonces sería razonable adaptar los programas de AF de forma tal que incluyan los factores ambientales adecuados para poder optimizar los beneficios del programa.

Hipótesis 3. Los beneficios neurocognitivos y de comportamiento son proporcionales al nivel de participación en AF que a su vez incluye retos cognitivos de dificultad adecuada. 
Los estudios sobre entrenamiento cognitivo computarizado han demostrado que los individuos solo mejoran en las áreas en las cuales fueron específicamente entrenados, pero estas mejoras no se transfieren a otras áreas o destrezas (Diamond \& Lee, 2011). Además, la evidencia sugiere que la AF que presenta retos cognitivos suele brindar mayores beneficios cognitivos que la AF que no reta la cognición (Diamond \& Lee, 2011). Por lo tanto, es lógico pensar que las artes marciales, las cuales desarrollan la concentración, pueden generar mayores beneficios en la concentración que otros juegos. Sin embargo, aunque esta hipótesis sobre especificidad no ha sido estudiada científicamente, la mayoría de los programas de AF incluyen actividades que promueven la función cognitiva. Por ejemplo, un programa de tenis de mesa le pidió a los niños y niñas que golpearan las pelotas de ciertos colores únicamente, lo que representa un reto a la inhibición (Pan et al., 2016). Ejercicios similares para mejorar la función cognitiva han sido incluidos en actividades sedentarias como el ajedrez y los dominós. Por tal razón, es posible que los niños y las niñas recibirán mayores beneficios de las actividades que les llamen más la atención y que los inviten a participar de las mismas. Si un niño o niña tiene pasión por el ajedrez y continuamente busca formas de mejorar su concentración mientras juega, entonces esto puede brindar mayores beneficios que la AF con retos cognitivos porque no participará de la AF.

\section{DiRecciones Futuras y Posibles Aplicaciones dURANTE el Diario ViViR}

Las publicaciones sobre AF y el TDAH están aumentando rápidamente. En términos de rigurosidad y cantidad, las publicacones no se acercan a aquellas que investigan tratamientos convencionales como el psicofarmacológico o el psicosocial. Sin embargo, los estudios transversales sugieren que los niños y niñas con TDAH presentan niveles de AF y de tiempo sedentario similares o mejores que los de sus pares aparentemente saludables durante la niñez. La niñez se considera el periodo en el cual ocurre la mayor cantidad de AF en forma de juego libre, pero las ventajas en AF y tiempo sedentario se disipan durante la adolescencia, la cual coincide con una gran cantidad de programas de AF estructurados y selectivos. Los estudios longitudinales sugieren que la AF durante etapas tempranas predice la severidad de los síntomas en etapas subsecuentes del desarrollo humano. La evidencia no demuestra definitivamente que la AF es un tratamiento eficaz contra el TDAH (como monoterapia o terapia adjunta); no obstante, los estudios que utilizaron AF de corta duración o de varias semanas sí han demostrado que la AF ayuda a complementar la terapia farmacológica. La literatura sobre la AF de corta duración sugiere que la AF tiene un rol positivo en las rutinas del diario vivir, sin embargo, poco se conoce sobre los efectos de la AF de corta duración fuera del ambiente del laboratorio (el comportamiento de niños y niñas en el salón de clases). En la literatura sobre intervenciones de AF de varias semanas existe la necesidad de realizar ensayos aleatorizados más rigurosos. También, estos estudios deben prestar más atención a las etapas del desarrollo, y perseguir ser estudios que mejoren la coordinación con programas o servicios de salud mental existentes y que integren medidas semanas después de la terminación de un programa. Las intervenciones de AF tienen el potencial de optimizar la integración de AF en coordinación con esfuerzos sobre la promoción de la salud mental y de maximizar los beneficios neurológicos durante el desarrollo.

En cuanto a las posibles aplicaciones a la vida diaria, los investigadores aun no pueden explicar cuál es la mejor forma de apoyar a las familias con niños o niñas con TDAH para que adopten 
AF como parte de su vida cotidiana. La mayoría de los estudios incluidos en esta revisión fueron realizados en las instalaciones universitarias o con recursos dentro de la universidad para motivar a los niños y niñas a realizar ejercicio. Sin embargo, estas condiciones no se pueden transferir a la población general ni a la mayoría de la población. Por tal razón, es necesaria la realización de estudios sobre intervenciones que incluyan a la comunidad y los servicios con un enfoque en la validez externa y en el potencial de ser diseminados. Hasta el momento, los estudios incluidos en esta revisión sugieren que los niños y niñas con TDAH se benefician particularmente de las intervenciones de AF que retan la cognición y mejoran las destrezas fundamentales de movimientos; al igual que la implementación de AF de corta duración durante el día de clase logra una máxima concentración durante periodos difíciles de la rutina diaria.

\section{Referencias:}

Arruda, M.A., Querido, C.N., Bigal, M.E., \& Polanczyk, G.V. (2015). ADHD and mental health status in Brazilian school-age children. Journal of attention disorders, 19(1), 11-17. DOI: https://doi.org/10.1177/1087054712446811

Ash, T., Bowling, A., Davison, K., \& Garcia, J. (2017). Physical activity interventions for children with social, emotional, and behavioral disabilities-a systematic review. Journal of Developmental \& Behavioral Pediatrics, 38(6), 431-445. DOI: https://doi.org/10.1097/dbp.0000000000000452

Barry, R.J., Clarke, A.R., Johnstone, S.J., Mccarthy, R., \& Selikowitz, M. (2009). Electroencephalogram $\theta / \beta$ ratio and arousal in attention-deficit/hyperactivity disorder: Evidence of independent processes. Biological psychiatry, 66(4), 398-401. DOI: https://doi.org/10.1016/i.biopsych.2009.04.027

Benzing, V., Chang, Y.-K., \& Schmidt, M. (2018). Acute physical activity enhances executive functions in children with ADHD. Scientific reports, 8(1), 12382. DOI: https://doi.org/10.1038/s41598-018-30067-8

Benzing, V., \& Schmidt, M. (2017). Cognitively and physically demanding exergaming to improve executive functions of children with attention deficit hyperactivity disorder: a randomised clinical trial. BMC pediatrics, 17(1), 8. DOI: https://doi.org/10.1186/s12887016-0757-9

Bird, H.R., Davies, M., Duarte, C.S., Shen, S., Loeber, R., \& Canino, G.J. (2006). A study of disruptive behavior disorders in Puerto Rican youth: II. Baseline prevalence, comorbidity, and correlates in two sites. Journal of the American Academy of Child \& Adolescent Psychiatry, 45(9), 1042-1053. DOI: https://doi.org/10.1097/01.chi.0000227879.65651.cf

Bowling, A., Slavet, J., Miller, D.P., Haneuse, S., Beardslee, W., \& Davison, K. (2017).

Cybercycling Effects on Classroom Behavior in Children With Behavioral Health Disorders: An RCT. Pediatrics, 139(2), e20161985. DOI: https://doi.org/10.1542/peds.2016-1985

Bustamante, E.E., Davis, C.L., Frazier, S.L., Rusch, D., Fogg, L.F., Atkins, M.S., \& Marquez, D.X. (2016). Randomized controlled trial of exercise for ADHD and disruptive behavior disorders. Medicine and science in sports and exercise, 48(7), 1397. DOI: https://doi.org/10.1249/mss.0000000000000891

Bustamante, E., Frazier, S., Mehta, T., \& Cua, G. (2018). North American Society for Pediatric Exercise Medicine (NASPEM) 2018 Conference Abstracts. Pediatric Exercise Science, 30(4 Suppl 1), S1-S34. DOI: https://journals.humankinetics.com/doi/pdf/10.1123/pes.2018-S1

Caspersen, C.J., Powell, K.E., \& Christenson, G.M. (1985). Physical activity, exercise, and physical fitness: definitions and distinctions for health-related research. Public health 
Actividad Física y TDAH

reports, $100(2), 126$. Retrieved from

https://www.ncbi.nlm.nih.gov/pmc/articles/PMC1424733/

Castaneda, R.L.A., Kumar, S., Voigt, R.G., Leibson, C.L., Barbaresi, W.J., Weaver, A.L., . . Katusic, S.K. (2016). Childhood attention-deficit/hyperactivity disorder, sex, and obesity: a longitudinal population-based study. Paper presented at the Mayo Clinic Proceedings. DOI: https://doi.org/10.1016/..mayocp.2015.09.017

Cerrillo-Urbina, A., García-Hermoso, A., Sánchez-López, M., Pardo-Guijarro, M., Santos Gómez, J., \& Martínez-Vizcaíno, V. (2015). The effects of physical exercise in children with attention deficit hyperactivity disorder: A systematic review and meta-analysis of randomized control trials. Child: care, health and development, 41(6), 779-788. DOI: https://doi.org/10.1111/cch.12255

Chiang, M.C., Mcmahon, K.L., De Zubicaray, G.I., Martin, N.G., Hickie, I., Toga, A.W., . . . Thompson, P.M. (2011). Genetics of white matter development: a DTI study of 705 twins and their siblings aged 12 to 29. Neuroimage, 54(3), 2308-2317. DOI: https://doi.org/10.1016/i.neuroimage.2010.10.015

Choi, J.W., Han, D.H., Kang, K.D., Jung, H.Y., \& Renshaw, P.F. (2015). Aerobic exercise and attention deficit hyperactivity disorder: brain research. Medicine and science in sports and exercise, 47(1), 33. DOI: https://doi.org/10.1249/mss.0000000000000373

Chou, C.-C., \& Huang, C.-J. (2017). Effects of an 8-week yoga program on sustained attention and discrimination function in children with attention deficit hyperactivity disorder. PeerJ, 5, e2883. DOI: https://doi.org/10.7717/peeri.2883

Chuang, L.-Y., Tsai, Y.-J., Chang, Y.-K., Huang, C.-J., \& Hung, T.-M. (2015). Effects of acute aerobic exercise on response preparation in a Go/No Go Task in children with ADHD: an ERP study. Journal of sport and Health science, 4(1), 82-88. DOI: https://doi.org/10.1016/i.jshs.2014.11.002

Cook, B.G., Li, D., \& Heinrich, K.M. (2015). Obesity, physical activity, and sedentary behavior of youth with learning disabilities and ADHD. Journal of learning disabilities, 48(6), 563576. DOI: https://doi.org/10.1177/0022219413518582

Cortese, S., Kelly, C., Chabernaud, C., Proal, E., Di Martino, A., Milham, M.P., \& Castellanos, F.X. (2012). Toward systems neuroscience of ADHD: a meta-analysis of $55 \mathrm{fMRI}$ studies. American Journal of Psychiatry, 169(10), 1038-1055. DOI: https://doi.org/10.1176/appi.ajp.2012.11101521

Cortese, S., Olazagasti, M.a.R., Klein, R.G., Castellanos, F.X., Proal, E., \& Mannuzza, S. (2013). Obesity in men with childhood ADHD: a 33-year controlled, prospective, followup study. Pediatrics, 131(6), e1731-e1738. DOI: https://doi.org/10.1542/peds.2012-0540

Cortese, S., \& Tessari, L. (2017). Attention-Deficit/Hyperactivity Disorder (ADHD) and Obesity: Update 2016. Current psychiatry reports, 19(1). DOI: https://doi.org/10.1007/s11920017-0754-1

Craft, D.H. (1983). Effect of prior exercise on cognitive performance tasks by hyperactive and normal young boys. Perceptual and Motor Skills, 56(3), 979-982. DOI: https://doi.org/10.2466/pms.1983.56.3.979

Curtin, C. (2015). Attention Deficit/Hyperactivity Disorder, Screen Time, Physical Activity, and Diet Quality. (PhD Dissertation), University of Massachusetts Medical School. Retrieved from https://www.researchgate.net/publication/283454646 Attention DeficitHyperactivity Dis order Screen Time Physical Activity and Diet Quality A Dissertation

Davey, C. P. (1973) Physical Exertion and Mental Performance, Ergonomics, 16:5, 595599, DOI: $10.1080 / 00140137308924550$

Davis, C.L., Tomporowski, P.D., Mcdowell, J.E., Austin, B.P., Miller, P.H., Yanasak, N.E., . . Naglieri, J.A. (2011). Exercise improves executive function and achievement and alters 
Actividad Física y TDAH

brain activation in overweight children: a randomized, controlled trial. Health Psychology, 30(1), 91. https://doi.org/10.1037/a0021766

Den Heijer, A.E., Groen, Y., Tucha, L., Fuermaier, A.B., Koerts, J., Lange, K.W., . . Tucha, O. (2017). Sweat it out? The effects of physical exercise on cognition and behavior in children and adults with ADHD: a systematic literature review. Journal of Neural Transmission, 124(1), 3-26. DOI: https://doi.org/10.1007/s00702-016-1593-7

Diamond, A. (2007). Consequences of variations in genes that affect dopamine in prefrontal cortex. Cerebral cortex, 17(suppl_1), i161-i170. DOI: https://doi.org/10.1093/cercor/bhm082

Diamond, A., \& Lee, K. (2011). Interventions shown to aid executive function development in children 4 to 12 years old. Science, 333(6045), 959-964. DOI: https://doi.org/10.1126/science.1204529

Ebenegger, V., Marques-Vidal, P.-M., Munsch, S., Quartier, V., Nydegger, A., Barral, J., .. . Puder, J.J. (2012). Relationship of hyperactivity/inattention with adiposity and lifestyle characteristics in preschool children. Journal of child neurology, 27(7), 852-858. DOI: https://doi.org/10.1177/0883073811428009

Engelhardt, L.E., Briley, D.A., Mann, F.D., Harden, K.P., \& Tucker-Drob, E.M. (2015). Genes unite executive functions in childhood. Psychological science, 26(8), 1151-1163. DOI: https://doi.org/10.1177/0956797615577209

Fenollar-Cortés, J., Gallego-Martínez, A., \& Fuentes, L.J. (2017). The role of inattention and hyperactivity/impulsivity in the fine motor coordination in children with ADHD. Research in developmental disabilities, 69, 77-84. DOI: https://doi.org/10.1016/j.ridd.2017.08.003

Fliers, E., Rommelse, N., Vermeulen, S., Altink, M., Buschgens, C., Faraone, S., . . Buitelaar, J. (2008). Motor coordination problems in children and adolescents with ADHD rated by parents and teachers: effects of age and gender. Journal of Neural Transmission, 115(2), 211-220. DOI: https://doi.org/10.1007/s00702-007-0827-0

Friedman, N.P., \& Miyake, A. (2017). Unity and diversity of executive functions: Individual differences as a window on cognitive structure. Cortex, 86, 186-204. DOI: https://doi.org/10.1016/i.cortex.2016.04.023

Friedman, N.P., Miyake, A., Young, S.E., Defries, J.C., Corley, R.P., \& Hewitt, J.K. (2008). Individual differences in executive functions are almost entirely genetic in origin. Journal of Experimental Psychology: General, 137(2), 201. DOI: https://doi.org/10.1037/00963445.137.2.201

Gapin, J., \& Etnier, J.L. (2010). The relationship between physical activity and executive function performance in children with attention-deficit hyperactivity disorder. Journal of Sport and Exercise Psychology, 32(6), 753-763. DOI: https://doi.org/10.1123/jsep.32.6.753

Gapin, J.I., Labban, J.D., Bohall, S.C., Wooten, J.S., \& Chang, Y.-K. (2015). Acute exercise is associated with specific executive functions in college students with ADHD: A preliminary study. Journal of sport and Health science, 4(1), 89-96. DOI: https://doi.org/10.1016/i.jshs.2014.11.003

Geladé, K., Bink, M., Janssen, T.W., Van Mourik, R., Maras, A., \& Oosterlaan, J. (2017). An $\mathrm{RCT}$ into the effects of neurofeedback on neurocognitive functioning compared to stimulant medication and physical activity in children with ADHD. European child \& adolescent psychiatry, 26(4), 457-468. DOI: https://doi.org/10.1007/s00787-016-0902-x

Golubović, Š., Milutinović, D., \& Golubović, B. (2014). Benefits of physical exercises in developing certain fitness levels in children with hyperactivity. Journal of psychiatric and mental health nursing, 21(7), 594-600. DOI: https://doi.org/10.1111/jpm.12091

Halperin, J.M. (2015). Body and Mind: Exercise and Play in Young Children with ADHD. Paper presented at the CHADD Annual International Conference on ADHD, New Orleans, LA. 
Actividad Física y TDAH

Halperin, J.M., Berwid, O.G., \& O'neill, S. (2014). Healthy body, healthy mind?: the effectiveness of physical activity to treat ADHD in children. Child and adolescent psychiatric clinics of North America, 23(4), 899-936. DOI: https://doi.org/10.1016/i.chc.2014.05.005

Halperin, J.M., \& Healey, D.M. (2011). The influences of environmental enrichment, cognitive enhancement, and physical exercise on brain development: Can we alter the developmental trajectory of ADHD? Neuroscience \& Biobehavioral Reviews, 35(3), 621 634. DOI: https://doi.org/10.1016/i.neubiorev.2010.07.006

Halperin, J.M., Marks, D.J., Bedard, A.-C.V., Chacko, A., Curchack, J.T., Yoon, C.A., \& Healey, D.M. (2013). Training executive, attention, and motor skills: a proof-of-concept study in preschool children with ADHD. Journal of attention disorders, 17(8), 711-721. DOI: https://doi.org/10.1177/1087054711435681

Harvey, W.J., Reid, G., Bloom, G.A., Staples, K., Grizenko, N., Mbekou, V., . . Joober, R. (2009). Physical activity experiences of boys with and without ADHD. Adapted Physical Activity Quarterly, 26(2), 131-150. DOI: https://doi.org/10.1123/apaq.26.2.131

Hillman, C.H., Pontifex, M.B., Castelli, D.M., Khan, N.A., Raine, L.B., Scudder, M.R., . . . Kamijo, K. (2014). Effects of the FITKids randomized controlled trial on executive control and brain function. Pediatrics, 134(4), e1063-e1071. DOI: https://doi.org/10.1542/peds.2013-3219

Howard, A.L., Robinson, M., Smith, G.J., Ambrosini, G.L., Piek, J.P., \& Oddy, W.H. (2011). ADHD is associated with a "Western" dietary pattern in adolescents. Journal of attention disorders, 15(5), 403-411. DOI: https://doi.org/10.1177/1087054710365990

Howie, E.K., Beets, M.W., \& Pate, R.R. (2014). Acute classroom exercise breaks improve ontask behavior in 4th and 5th grade students: a dose-response. Mental Health and Physical Activity, 7(2), 65-71. DOI: https://doi.org/10.1016/i.mhpa.2014.05.002

Hoza, B., Martin, C.P., Pirog, A., \& Shoulberg, E.K. (2016). Using physical activity to manage ADHD symptoms: the state of the evidence. Current psychiatry reports, 18(12), 113. DOI: https://doi.org/10.1007/s11920-016-0749-3

Hoza, B., Smith, A.L., Shoulberg, E.K., Linnea, K.S., Dorsch, T.E., Blazo, J.A., . . Mccabe, G.P. (2015). A randomized trial examining the effects of aerobic physical activity on attention-deficit/hyperactivity disorder symptoms in young children. Journal of abnormal child psychology, 43(4), 655-667. DOI: https://doi.org/10.1007/s10802-014-9929-y

Jensen, P.S., Hinshaw, S.P., Swanson, J.M., Greenhill, L.L., Conners, C.K., Arnold, L.E., . . Hoza, B. (2001). Findings from the NIMH Multimodal Treatment Study of ADHD (MTA): implications and applications for primary care providers. Journal of Developmental \& Behavioral Pediatrics, 22(1), 60-73. DOI: https://doi.org/10.1097/00004703-200102000$\underline{00008}$

Jeong, S.H., Choi, K.-S., Lee, K.Y., Kim, E.-J., Kim, Y.-S., \& Joo, E.-J. (2015). Association between the dopamine transporter gene (DAT1) and attention deficit hyperactivity disorder-related traits in healthy adults. Psychiatric genetics, 25(3), 119-126. DOI: https://doi.org/10.1097/ypg.0000000000000086

Kaiser, M.-L., Schoemaker, M., Albaret, J.-M., \& Geuze, R. (2015). What is the evidence of impaired motor skills and motor control among children with attention deficit hyperactivity disorder (ADHD)? Systematic review of the literature. Research in developmental disabilities, 36, 338-357. DOI: https://doi.org/10.1016/..ridd.2014.09.023

Kang, K., Choi, J., Kang, S., \& Han, D. (2011). Sports therapy for attention, cognitions and sociality. International journal of sports medicine, 32(12), 953-959. DOI: https://doi.org/10.1055/s-0031-1283175

Khalife, N., Kantomaa, M., Glover, V., Tammelin, T., Laitinen, J., Ebeling, H., . . Rodriguez, A. (2014). Childhood attention-deficit/hyperactivity disorder symptoms are risk factors for obesity and physical inactivity in adolescence. Journal of the American Academy of 
Actividad Física y TDAH

Child \& Adolescent Psychiatry, 53(4), 425-436. DOI:

https://doi.org/10.1016/i.jaac.2014.01.009

Lewallen, T.C., Hunt, H., Potts-Datema, W., Zaza, S., \& Giles, W. (2015). The Whole School, Whole Community, Whole Child model: a new approach for improving educational attainment and healthy development for students. Journal of School Health, 85(11), 729739. DOI: https://doi.org/10.1111/josh.12310

Lin, C.-Y., Yang, A.-L., \& Su, C.-T. (2013). Objective measurement of weekly physical activity and sensory modulation problems in children with attention deficit hyperactivity disorder. Research in developmental disabilities, 34(10), 3477-3486. DOI: https://doi.org/10.1016/.ridd.2013.07.021

Lubans, D.R., Morgan, P.J., Cliff, D.P., Barnett, L.M., \& Okely, A.D. (2010). Fundamental movement skills in children and adolescents. Sports medicine, 4O(12), 1019-1035. DOI: https://doi.org/10.2165/11536850-000000000-00000

Ludyga, S., Brand, S., Gerber, M., Weber, P., Brotzmann, M., Habibifar, F., \& Pühse, U. (2017). An event-related potential investigation of the acute effects of aerobic and coordinative exercise on inhibitory control in children with ADHD. Developmental cognitive neuroscience, 28, 21-28. DOI: https://doi.org/10.1016/i.dcn.2017.10.007

Mahar, M.T., Murphy, S.K., Rowe, D.A., Golden, J., Shields, A.T., \& Raedeke, T.D. (2006). Effects of a classroom-based program on physical activity and on-task behavior. Medicine and science in sports and exercise, 38(12), 2086. DOI: https://doi.org/10.1249/01.mss.0000235359.16685.a3

Mahon, A.D., Dean, R.S., Mcintosh, D.E., Marjerrison, A.D., Cole, A.S., Woodruff, M.E., \& Lee, M.P. (2013). Acute exercise effects on measures of attention and impulsivity in children with attention deficit/hyperactivity disorder. Journal of Educational and Developmental Psychology, 3(2), 65. DOI: https://doi.org/10.5539/jedp.v3n2p65

Martinson, T., Butterfield, S.A., Mason, C.A., Tu, S., Lehnhard, R.A., \& Nightingale, C.J. (2018). PACER Performance of Children Aged 11-14 With Attention-Deficit Hyperactive Disorder. Pediatric exercise science, 30(2), 237-242. DOI: https://doi.org/10.1123/pes.2017-0048

Mcneill, J., Howard, S.J., Vella, S.A., Santos, R., \& Cliff, D.P. (2018). Physical activity and modified organized sport among preschool children: Associations with cognitive and psychosocial health. Mental Health and Physical Activity, 15, 45-52. DOI: https://doi.org/10.1016/..mhpa.2018.07.001

Medina, J.A., Netto, T.L., Muszkat, M., Medina, A.C., Botter, D., Orbetelli, R., . . Miranda, M.C. (2010). Exercise impact on sustained attention of ADHD children, methylphenidate effects. ADHD Attention Deficit and Hyperactivity Disorders, 2(1), 49-58. DOI: https://doi.org/10.1007/s12402-009-0018-y

Montiel, C., Peña, J.A., Montiel-Barbero, I., \& Polanczyk, G. (2008). Prevalence rates of attention deficit/hyperactivity disorder in a school sample of Venezuelan children. Child psychiatry and human development, 39(3), 311-322. DOI: https://doi.org/10.1007/s10578-007-0090-5

Mulrine, C.F., Prater, M.A., \& Jenkins, A. (2008). The active classroom: Supporting students with attention deficit hyperactivity disorder through exercise. Teaching exceptional children, 40(5), 16-22. DOI: https://doi.org/10.1177/004005990804000502

Neudecker, C., Mewes, N., Reimers, A.K., \& Woll, A. (2015). Exercise interventions in children and adolescents with ADHD: a systematic review. Journal of attention disorders, 1087054715584053. DOI: https://doi.org/10.1177/1087054715584053

Ng, Q.X., Ho, C.Y.X., Chan, H.W., Yong, B.Z.J., \& Yeo, W.-S. (2017). Managing childhood and adolescent attention-deficit/hyperactivity disorder (ADHD) with exercise: a systematic review. Complementary therapies in medicine, 34, 123-128. DOI: https://doi.org/10.1016/i.ctim.2017.08.018 
Actividad Física y TDAH

Ogoh, S., \& Ainslie, P.N. (2009). Regulatory mechanisms of cerebral blood flow during exercise: new concepts. Exercise and sport sciences reviews, 37(3), 123-129. DOI: https://doi.org/10.1097/jes.0b013e3181aa64d7

Pan, C.-Y., Chang, Y.-K., Tsai, C.-L., Chu, C.-H., Cheng, Y.-W., \& Sung, M.-C. (2017). Effects of physical activity intervention on motor proficiency and physical fitness in children with ADHD: An exploratory study. Journal of attention disorders, 21(9), 783-795. DOI: https://doi.org/10.1177/1087054714533192

Pan, C.-Y., Chu, C.-H., Tsai, C.-L., Lo, S.-Y., Cheng, Y.-W., \& Liu, Y.-J. (2016). A racket-sport intervention improves behavioral and cognitive performance in children with attentiondeficit/hyperactivity disorder. Research in developmental disabilities, 57, 1-10. DOI: https://doi.org/10.1016/i.ridd.2016.06.009

Piepmeier, A.T., Shih, C.-H., Whedon, M., Williams, L.M., Davis, M.E., Henning, D.A., . . . Etnier, J.L. (2015). The effect of acute exercise on cognitive performance in children with and without ADHD. Journal of sport and Health science, 4(1), 97-104. DOI: https://doi.org/10.1016/i.jshs.2014.11.004

Piercy, K.L., Troiano, R.P., Ballard, R.M., Carlson, S.A., Fulton, J.E., Galuska, D.A., .. Olson, R.D. (2018). The physical activity guidelines for Americans. Jama, 320(19), 2020-2028. DOI: https://doi.org/10.1001/jama.2018.14854

Pontifex, M.B., Saliba, B.J., Raine, L.B., Picchietti, D.L., \& Hillman, C.H. (2013). Exercise improves behavioral, neurocognitive, and scholastic performance in children with attention-deficit/hyperactivity disorder. The Journal of pediatrics, 162(3), 543-551. DOI: https://doi.org/10.1016/i.jpeds.2012.08.036

Ramer, J., Hawkins, M., Hilgenkamp, T., Santiago-Rodríguez, M.E., \& Bustamante, E.E. (2019). Objectivey-Measured Physical Activity and Sedentary Time by ADHD Diagnosis:

NHANES 2003-2004. Annals of Behavioral Medicine, 53(S1), S369. DOI: https://academic.oup.com/abm/article/53/Supplement 1/S1/5370264

Ramer, J.D., Davis, C.L., Frazier, S.L., Marquez, D.X., \& Bustamante, E.E. (2018). Physical Activity Influence On Behavior Of Children With Adhd \& Dbd During Instruction Using Classroom Observation. Medicine \& Science in Sports \& Exercise, 50(5S), 693. DOI: https://doi.org/10.1249/01.mss.0000538283.55074.7a

Ridgway, A., Northup, J., Pellegrin, A., Larue, R., \& Hightsoe, A. (2003). Effects of recess on the classroom behavior of children with and without attention-deficit hyperactivity disorder. School Psychology Quarterly, 18(3), 253. DOI: https://doi.org/10.1521/scpq.18.3.253.22578

Rommel, A.-S., Lichtenstein, P., Rydell, M., Kuja-Halkola, R., Asherson, P., Kuntsi, J., \& Larsson, H. (2015). Is physical activity causally associated with symptoms of attentiondeficit/hyperactivity disorder? Journal of the American Academy of Child \& Adolescent Psychiatry, 54(7), 565-570. DOI: https://doi.org/10.1016/j.jaac.2015.04.011

Schaeffer, D.J., Krafft, C.E., Schwarz, N.F., Chi, L., Rodrigue, A.L., Pierce, J.E., . . Davis, C.L. (2014). An 8-month exercise intervention alters frontotemporal white matter integrity in overweight children. Psychophysiology, 51(8), 728-733. DOI: https://doi.org/10.1111/psyp.12227

Shimoni, M.A., Engel-Yeger, B., \& Tirosh, E. (2010). Participation in leisure activities among boys with attention deficit hyperactivity disorder. Research in developmental disabilities, 31(6), 1234-1239. DOI: https://doi.org/10.1016/i.ridd.2010.07.022

Song, M., Lauseng, D., Lee, S., Nordstrom, M., \& Katch, V. (2016). Enhanced physical activity improves selected outcomes in children with ADHD: Systematic review. Western journal of nursing research, 38(9), 1155-1184. DOI: https://doi.org/10.1177/0193945916649954

State of Play 2017: Trends and Developments. (2017). Retrieved from https://www.aspeninstitute.org/publications/state-of-play-2017-trends-and-developments/ 
Actividad Física y TDAH

Suarez-Manzano, S., Ruiz-Ariza, A., De La Torre-Cruz, M., \& Martinez-Lopez, E.J. (2018). Acute and chronic effect of physical activity on cognition and behaviour in young people with ADHD: A systematic review of intervention studies. Research in developmental disabilities, 77, 12-23. DOI: https://doi.org/10.1016/i.ridd.2018.03.015

Swanson, J., Sunohara, G., Kennedy, J., Regino, R., Fineberg, E., Wigal, T., ... Wigal, S. (1998). Association of the dopamine receptor D4 (DRD4) gene with a refined phenotype of attention deficit hyperactivity disorder (ADHD): a family-based approach. Molecular psychiatry, 3(1), 38. DOI: https://doi.org/10.1038/sj.mp.4000354

Tan, B.W., Pooley, J.A., \& Speelman, C.P. (2016). A meta-analytic review of the efficacy of physical exercise interventions on cognition in individuals with autism spectrum disorder and ADHD. Journal of autism and developmental disorders, 46(9), 3126-3143. DOI: https://doi.org/10.1007/s10803-016-2854-x

Tantillo, M., Kesick, C.M., Hynd, G.W., \& Dishman, R.K. (2002). The effects of exercise on children with attention-deficit hyperactivity disorder. Medicine \& Science in Sports \& Exercise. DOI: https://doi.org/10.1097/00005768-200202000-00004

Verburgh, L., Königs, M., Scherder, E.J., \& Oosterlaan, J. (2014). Physical exercise and executive functions in preadolescent children, adolescents and young adults: a metaanalysis. Br J Sports Med, 48(12), 973-979. DOI: https://doi.org/10.1136/bjsports-2012091441

Verret, C., Gardiner, P., \& Béliveau, L. (2010). Fitness level and gross motor performance of children with attention-deficit hyperactivity disorder. Adapted Physical Activity Quarterly, 27(4), 337-351. DOI: https://doi.org/10.1123/apaq.27.4.337

Verret, C., Guay, M.-C., Berthiaume, C., Gardiner, P., \& Béliveau, L. (2012). A physical activity program improves behavior and cognitive functions in children with ADHD: an exploratory study. Journal of attention disorders, 16(1), 71-80. DOI: https://doi.org/10.1177/1087054710379735

Vicente, B., Saldivia, S., De La Barra, F., Kohn, R., Pihan, R., Valdivia, M., ... Melipillan, R. (2012). Prevalence of child and adolescent mental disorders in Chile: a community epidemiological study. Journal of child psychology and psychiatry, 53(10), 1026-1035. DOI: https://doi.org/10.1111/j.1469-7610.2012.02566.x

Visser, S.N., Deubler, E.L., Bitsko, R.H., Holbrook, J.R., \& Danielson, M.L. (2016). Demographic differences among a national sample of US youth with behavioral disorders. Clinical pediatrics, 55(14), 1358-1362. DOI: https://doi.org/10.1177/0009922815623229

Volkow, N.D., Wang, G.-J., Fowler, J.S., \& Ding, Y.-S. (2005). Imaging the effects of methylphenidate on brain dopamine: new model on its therapeutic actions for attentiondeficit/hyperactivity disorder. Biological psychiatry, 57(11), 1410-1415. DOI: https://doi.org/10.1016/j.biopsych.2004.11.006

Volkow, N.D., Wang, G.-J., Kollins, S.H., Wigal, T.L., Newcorn, J.H., Telang, F., . . Ma, Y. (2009). Evaluating dopamine reward pathway in ADHD: clinical implications. Jama, 302(10), 1084-1091. DOI: https://doi.org/10.1001/jama.2009.1308

Vysniauske, R., Verburgh, L., Oosterlaan, J., \& Molendijk, M.L. (2016). The effects of physical exercise on functional outcomes in the treatment of ADHD: a meta-analysis. Journal of attention disorders, 1087054715627489 . DOI: https://doi.org/10.1177/1087054715627489

Watson, A., Timperio, A., Brown, H., Hinkley, T., \& Hesketh, K.D. (2019). Associations between organised sport participation and classroom behaviour outcomes among primary schoolaged children. PloS one, 14(1), e0209354. DOI: https://doi.org/10.1371/journal.pone.0209354

Wendt, M.S. (2000). The effect of an activity program designed with intense physical exercise on the behavior of attention deficit hyperactivity disorder (ADHD) children. State University of New York at Buffalo. Retrieved from 
https://books.google.co.cr/books/about/The Effect of an Activity Program Design.html ?id=xv77NwAACAAJ\&redir esc $=y$

Wigal, S.B., Nemet, D., Swanson, J.M., Regino, R., Trampush, J., Ziegler, M.G., \& Cooper, D.M. (2003). Catecholamine response to exercise in children with attention deficit hyperactivity disorder. Pediatric research, 53(5), 756. DOI: https://doi.org/10.1203/01.pdr.0000061750.71168.23

Willcutt, E.G., Doyle, A.E., Nigg, J.T., Faraone, S.V., \& Pennington, B.F. (2005). Validity of the executive function theory of attention-deficit/hyperactivity disorder: a meta-analytic review. Biological psychiatry, 57(11), 1336-1346. DOI:

https://doi.org/10.1016/i.biopsych.2005.02.006 